\title{
PERANCANGAN CUT OFF SEBAGAI PEMUTUS TEGANGAN DAN ARUS SISTEM CHARGING BATERAI
}

\author{
Pratama Ludfia Dendi Prihananto*), Mochammad Facta, Sudjadi \\ Departemen Teknik Elektro, Universitas Diponegoro \\ J1. Prof. Sudharto, SH, Kampus UNDIP Tembalang, Semarang 50275, Indonesia \\ ${ }^{*}$ E-mail: pratamaludfia@gmail.com
}

\begin{abstract}
Abstrak
Proses pengisian akumulator perlu memperhatikan nilai arus dan tegangan yang mengalir ke akumulator. Waktu pengisian dan usia akumulator sangat bergantung pada sifat rangkaian pengisi akumulator. Arus dan tegangan yang tidak sesuai dapat merusak akumulator dan mengurangi umur akumulator. Masalah tersebut dapat diatasi dengan menggunakan rangkaian cut off tegangan dan arus. Pemilihan rangkaian cut off menggunakan transistor sebagai alat pemutus tegangan dan arus memiliki kelebihan yaitu mampu memutus tegangan dan arus sesuai yang dibatasi tanpa perlu mengganti komponen.Berdasarkan hasil pengujian, rangkaian cut off dapat memutus tegangan dan arus keluaran sesuai yang dibatasi. Berdasarkan hasil pengukuran, rangkaian cut off mampu memutus tegangan dan arus pada tegangan $13.4 \mathrm{~V}$ dan arus $0.012 \mathrm{~A}$ pada baterai $1.2 \mathrm{Ah}$.
\end{abstract}

Kata kunci: Pengisian Akumulator, Cut Off, Transistor

\begin{abstract}
Accumulator charging process need to concern about the value of current and voltage that flows to it. The accumulation time and age depend on the characterisric of the accumulator inside circuit. Excessive currents and voltages can damage the accumulator and reduce the life of the accumulator. This problem can be overcome by using a voltage and current cut-off circuit.In this work, the Cut Off circuit is proposed by using a transistor as a breaker voltage and current has the advantage to break the voltage and current according to the adjusted limit without the requirement of the circuit component replacement. Based on the test results, the cut off circuit can break the output voltage and current according to the limit based on the measurement results, the cut-off circuit is able to break the voltage and current at a voltage of 13.4 V and a current of 0.012 A on a 1.2 Ah battery.
\end{abstract}

Keywords: Accumulator Charge, Cut Off, Transistor

\section{Pendahuluan}

Sumber energi terbarukan merupakan energi yang tak akan habis, bersih, dan dapat digunakan secara desentralisasi. Selain itu juga, energi terbarukan juga memiliki keuntungan, yaitu secara cuma-cuma dapat di ambil dari alam dan dapat diintergrasikan dengan jenisjenis sumber energi terbarukan lain. Salah satu masalah yang timbul dengan penggunaan energi terbarukan adalah media untuk menyimpan energi tersebut karena tidak terus menerusnya energi dari sumber terbarukan yang dihasilkan, misalnya sumber energi dari sel surya tidak akan menghasilkan energi saat malam hari sehingga dibutuhkan media penyimpanan energi yang menyimpan energi yang dihasilkan selama siang hari dan dapat menggunakannya pada malam hari.[1]

Salah satu media penyimpanan energi adalah baterai. Penyimpanan dan konversi energi akan menjadi sangat terkait dengan perkembangan energi terbarukan.
Penggunaan baterai sebagai media penyimpanan energi diharapkan dapat menjadi teknologi yang sangat penting dalam perkembangan energi terbarukan. [1]

Akumulator merupakan komponen penyimpanan energi listrik yang dapat dipindah pindah dan mampu menyimpan energi listrik melalui proses kimia sehingga energi listrik dapat digunakan pada waktu yang lain. [2]

Akumulator banyak digunakan dalam berbagai macam aplikasi, seperti aplikasi dalam bidang telekomunikasi, Uninterruptible Power Supply (UPS), sistem alarm kebakaran, photovoltaic, bahkan untuk aplikasi medis[3]. Pengisian akumulator yang tepat dapat mempercepat waktu pengisian dan tidak mengurangi usia akumulator. Waktu pengisian dan usia akumulator sangat bergantung pada sifat rangkaian pengisi akumulator tersebut[4].

Penelitian ini akan merancang sebuah rangkaian Cut Off Charger untuk diimplementasikan pada sistem Pengisian Akumulator. Pemilihan rangkaian Cut Off Charger 
menggunakan transistor sebagai alat pembatas tegangan dan arus dan pada sistem Pengisian Akumulator ini memiliki kelebihan yaitu mampu memutus tegangan dan arus sesuai yang dibatasi tanpa perlu mengganti komponen.

Hasil dari penelitian implementasi Cut Off Charger pada sistem Pengisian Akumulator diharapkan dapat digunakan sebagai referensi alat pemutus tegangan dan arus pada perangkat elektronika daya sesuai dengan kebutuhan.

Berdasarkan penelitian terdahulu telah dibuat rangkaian Cut Off Charger dimana rangkaian tersebut hanya dapat memutus tegangan dan arus, tetapi Penelitian ini berbeda dengan penelitian terdahulu yaitu mampu mensuplay beban ketika pengisian baterai sudah mencapai penuh [5].

Pada penelitian lainnya yaitu menggunakan SCR sebagai pengganti Transistor [6]. Prinsip kerjanya hampir sama dengan transitor yaitu dapat memicu relay ketika tegangan tertentu, sesuai dengan tegangan dioda zener yang ditentukan.

Pada penelitian lainnya yaitu menggunakan LM741 sebagai pengganti Transistor [7]. Prinsip kerjanya yaitu IC LM741 sebagai komparator untuk mengaktifkan relay, yang digunakan sebagai pemutus tegangan dan arus pengisian.

\section{Metode}

Sumber pengisian baterai berasal dari modul Buck Converter dengan tegangan 14 Volt DC. Sedangkan, suplay rangkaian berasal dari baterai 6 Volt DC yang dinaikkan tegangannya dengan modul penaik tegangan menjadi 15 Volt DC blok diagram rangkaian cut off dapat dilihat pada Gambar 1.



Gambar 1. Blok Diagram Alat

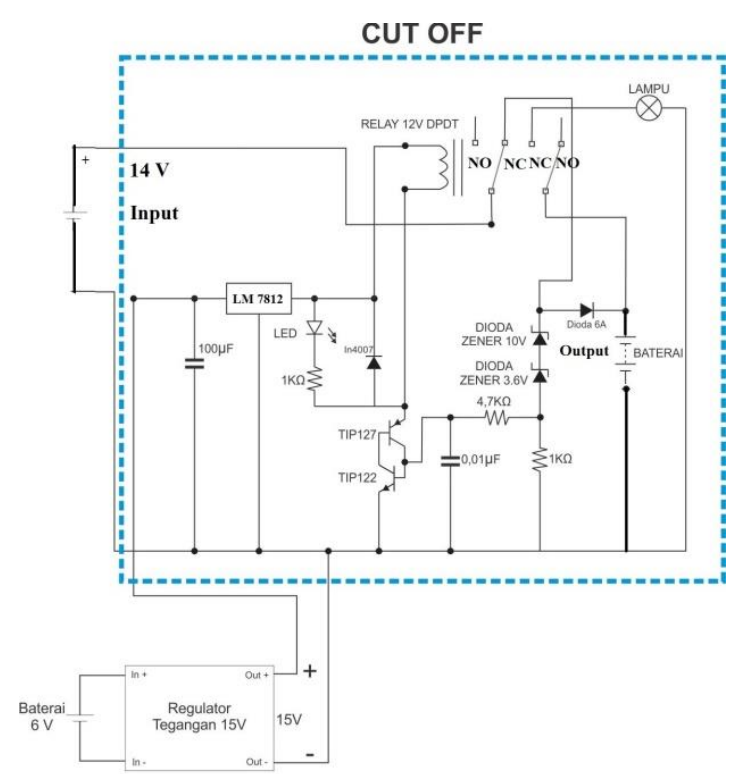

Gambar 2. Rangkaian Cut Off

\subsection{Komponen Cut Off}

Gambar 2 merupakan rangkaian current limiter pada Penelitian ini tersusun dari komponen-komponen berikut::

1. Transistor

2. Resistor

3. LM 7812

4. Relay $12 \mathrm{~V}$

5. Dioda

6. Dioda zener

7. Kapasitor

\subsection{Realisasi Rangkaian Cut Off}

Cut off relay merupakan relay pemutus otomatis ketika tegangan mencapai tegangan tertentu. Rangkaian ini terdiri dari relay, transistor, dioda zener, switch, kapasitor dan resistor. Gambar 3 adalah rangkaian dari cut off relay.

Prinsip kerja dari rangkaian ini adalah dengan menggunakan relay $12 \mathrm{~V}$ sebagai pemutusnya. Sebelum relay ini dalam keadaan normally open maka dibutuhkan transistor untuk agar tidak arus listrik yang mengalir dari kumparan coil ke ground sebelum terjadi adanya pemicuan dari transistor. Ketika transistor diberi pemicuan, maka akan terjadi bias maju pada transistor sehingga arus listrik mengalir ke ground yang menyebabkan relay menjadi normally open dan LED akan menyala[9]. 
Fungsi dari LM 7812 adalah untuk membatasi tegangan yang masuk ke relay agar tidak lebih dari 12 volt. Menurut datasheet, tegangan maksimal yang dapat diterima adalah sebesar $110 \%$ dari tegangan nominal relaynya. Artinya, relay 12 volt hanya mampu menerima tegangan sebesat 13,2 volt [8] .

Pada rangkaian ini diberi switch untuk mereset transistor ketika dalam kondisi bias maju. Apabila transistor telah dipicu maka LED akan terus menyala dan salah satu cara untuk menghentikan bias maju pada transistor adalah dengan memberikan jalan lain ke ground agar tidak melalui transistor tersebut. Salah satu caranya adalah dengan memberikan switch yang diparalel dengan transistor. Switch ini merupakan push button dengan kondisi normally open. Jadi dalam kondisi normal, switch akan open, apabila switch ini ditekan maka akan dalam kondisi closed.

Pengaturan batas maksimum tegangan diatur dengn menentukan dioda zener. Dioda zener dipasang paralel dengan akumulator untuk memicu transistor ketika dioda zener melampaui tegangan tembusnya. Oleh karena itu pada Gambar 3 diperlukan 2 dioda zener yang dipasang seri $(10 \mathrm{~V}$ dan $3.6 \mathrm{~V})$. Pemicuan transistor itu sendiri berasal dari dioda zener yang mana apabila tegangan pada akumulator melampui tegangan breakdown nya maka akan terjadi reverse bias (bias balik) sehingga arus akan mengalir ke transistor.



Gambar 3. Realisasi Cut Off

\section{Hasil dan Analisis}

\subsection{Pengujian Rangkaian Cut Off Tanpa Beban}

Pengujian ini merupakan pengujian rangkaian Cut Off tanpa beban dengan baterai 1.2 Ah. Tegangan dan arus diukur menggunakan multimeter SANWA PC5000 dengan probe tegangan dihubung paralel dengan probe arus dihubung seri dengan baterai. Berikut merupakan data yang diambil pada rangkaian Cut Off tanpa beban.

Pada tabel 1 dapat dilihat bahwa tegangan suplay rangkaian yaitu sebesar $15 \mathrm{~V}$, tegangan sumber pengisian baterai yaitu antara $9 \mathrm{~V}$ sampai $15 \mathrm{~V}$. Kemudian dapat dilihat bahwa pada tegangan pengisian $9 \mathrm{~V}-14 \mathrm{~V}$ relay dalam keadaan Normally Close (NC). Sedangkan pada tegangan pengisian $14.2 \mathrm{~V}$ relay sudah dalam keadaan Normally Open (NO).

Tabel 1. Data pengujian rangkaian cut off tanpa beban baterai 1.2 Ah.

\begin{tabular}{lllll}
\hline $\begin{array}{l}\text { V Pengisian } \\
(\mathrm{V})\end{array}$ & $\begin{array}{l}\text { I Pengisian } \\
(\mathrm{A})\end{array}$ & $\begin{array}{l}\text { V Baterai } \\
(\mathrm{V})\end{array}$ & $\begin{array}{l}\text { I Baterai } \\
(\mathrm{A})\end{array}$ & $\begin{array}{l}\text { Kondisi } \\
\text { Relay }\end{array}$ \\
\hline 9 & 0.0009 & 12.575 & 0.0002 & $\mathrm{NC}$ \\
9.2 & 0.0008 & 12.575 & 0.0001 & $\mathrm{NC}$ \\
9.5 & 0.0007 & 12.575 & 0.0002 & $\mathrm{NC}$ \\
9.7 & 0.0008 & 12.575 & 0.0002 & $\mathrm{NC}$ \\
10 & 0.0008 & 12.575 & 0.0002 & $\mathrm{NC}$ \\
10.2 & 0.0009 & 12.575 & 0.0001 & $\mathrm{NC}$ \\
10.5 & 0.0008 & 12.575 & 0.0002 & $\mathrm{NC}$ \\
10.7 & 0.0008 & 12.575 & 0.0002 & $\mathrm{NC}$ \\
11.0 & 0.0008 & 12.575 & 0.0002 & $\mathrm{NC}$ \\
11.2 & 0.0009 & 12.575 & 0.0002 & $\mathrm{NC}$ \\
11.5 & 0.0009 & 12.575 & 0.0002 & $\mathrm{NC}$ \\
11.7 & 0.0009 & 12.575 & 0.0002 & $\mathrm{NC}$ \\
12.0 & 0.0010 & 12.575 & 0.0002 & $\mathrm{NC}$ \\
12.2 & 0.0010 & 12.578 & 0.0002 & $\mathrm{NC}$ \\
12.5 & 0.0011 & 12.578 & 0.0002 & $\mathrm{NC}$ \\
12.7 & 0.0011 & 12.578 & 0.0001 & $\mathrm{NC}$ \\
13.0 & 0.0018 & 12.582 & 0.0006 & $\mathrm{NC}$ \\
13.2 & 0.0062 & 12.612 & 0.0051 & $\mathrm{NC}$ \\
13.5 & 0.0272 & 12.828 & 0.0141 & $\mathrm{NC}$ \\
13.7 & 0.0930 & 12.937 & 0.0772 & $\mathrm{NC}$ \\
14.0 & 0.1819 & 13.202 & 0.1721 & $\mathrm{NC}$ \\
14.2 & 0.2120 & 13.417 & 0.0120 & $\mathrm{NO}$ \\
14.5 & 0.2739 & 13.120 & 0.0120 & $\mathrm{NO}$ \\
14.7 & 0.3209 & 12.958 & 0.0120 & $\mathrm{NO}$ \\
15.0 & 0.4321 & 12.810 & 0.0120 & $\mathrm{NO}$ \\
\hline & & & &
\end{tabular}

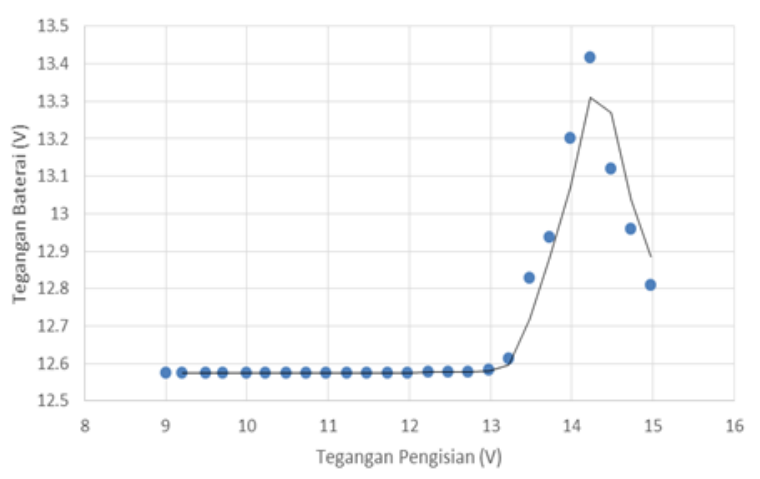

Gambar 4. Hubungan tegangan pengisian dengan tegangan baterai rangkaian cut off dengan baterai 1.2 Ah tanpa beban

Gambar 4 merupakan hubungan antara tegangan pengisian dengan tegangan baterai, dapat dilihat bahwa tegangan pengisian dengan tegangan baterai berbanding lurus, semakin naik tegangan pengisian maka tegangan baterai juga semakin naik. Tegangan pengisian mulai dari $9 \mathrm{~V}$ sampai $15 \mathrm{~V}$. Pada saat tegangan pengisian dari $9 \mathrm{~V}$ sampai $12.7 \mathrm{~V}$, tegangan baterai masih belum naik yaitu pada tegangan 12.575 V.Namun pada tegangan $13 \mathrm{~V}$ tegangan baterai mulai naik. Hal ini disebabkan karena tegangan baterai lebih kecil daripada tegangan pengisian 
sehingga tegangan baterai akan naik. Dapat dilihat bahwa pada tegangan baterai $13.417 \mathrm{~V}$ relay dalam kondisi Normally Open (NO). Kemudian setelah itu tegangan mengalami penurunan.

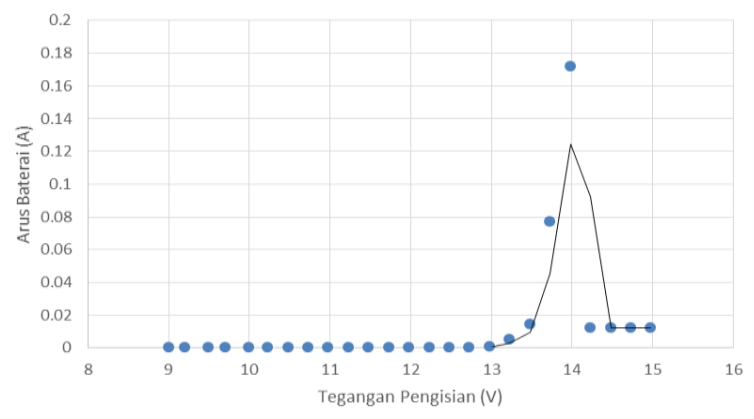

Gambar 5. Hubungan tegangan pengisian dengan arus baterai rangkaian cut off dengan baterai 1.2 Ah tanpa beban

Gambar 5 merupakan hubungan antara tegangan pengisian dengan arus baterai, dapat dilihat bahwa tegangan pengisian dengan arus pengisian berbanding lurus, semakin naik tegangan pengisian maka arus baterai juga semakin naik.. Pada saat tegangan pengisian dari $9 \mathrm{~V}$ sampai $12.7 \mathrm{~V}$, arus pengisian masih belum naik yaitu pada $0.001 \mathrm{~A}$.Namun pada tegangan $13 \mathrm{~V}$ arus pengisian mulai naik. Hal ini disebabkan karena arus baterai mengikuti tegangan pengisian, semakin naik tegangan pengisian maka arus baterai juga semakin naik. Dapat dilihat bahwa pada tegangan pengisian $14.2 \mathrm{~V}$ relay dalam kondisi Normally Open (NO). Kemudian setelah itu arus mengalami penurunan.

\subsection{Pengujian Rangkaian Cut Off Menggunakan Beban}

Pengujian ini merupakan pengujian rangkaian Cut Off menggunakan beban dengan baterai 1.2 Ah. Tegangan dan arus diukur menggunakan multimeter SANWA PC5000 dengan probe tegangan dihubung paralel dengan probe arus dihubung seri dengan baterai . Berikut merupakan data yang diambil pada rangkaian Cut Off menggunakan beban.

Tabel 2. Data pengujian rangkaian cut off menggunakan beban baterai $1.2 \mathrm{Ah}$.

\begin{tabular}{lllll}
\hline $\begin{array}{l}\text { V Suplay } \\
(\mathrm{V})\end{array}$ & $\begin{array}{l}\text { V Pengisian } \\
(\mathrm{V})\end{array}$ & $\begin{array}{l}\text { V } \\
\text { Beban } \\
(\mathrm{V})\end{array}$ & $\begin{array}{l}\text { I Beban } \\
(\mathrm{V})\end{array}$ & $\begin{array}{l}\text { Beban } \\
(\text { Ohm })\end{array}$ \\
\hline 15 & 14.294 & 11.960 & 0.2520 & 47 \\
15 & 14.294 & 12.161 & 0.1845 & 68 \\
15 & 14.294 & 12.225 & 0.1491 & 82 \\
15 & 14.294 & 12.248 & 0.1206 & 100 \\
15 & 14.294 & 12.458 & 0.1011 & 120 \\
15 & 14.294 & 12.618 & 0.0698 & 180 \\
15 & 14.294 & 12.621 & 0.0646 & 200 \\
15 & 14.294 & 12.648 & 0.0545 & 220 \\
15 & 14.294 & 12.653 & 0.0476 & 270 \\
15 & 14.294 & 12.714 & 0.0383 & 330 \\
\hline
\end{tabular}

Pada tabel 2 dapat dilihat bahwa tegangan suplay baterai yaitu sebesar $15 \mathrm{~V}$, tegangan sumber pengisian baterai yaitu $14.294 \mathrm{~V}$. Pada tegangan $14.294 \mathrm{~V}$ relay yang menuju ke baterai sudah dalam kondisi Normally Open (NO) . Sedangkan Relay yang menuju ke beban dalam kondisi Normally Close (NC). Pada kondisi ini beban tersambung dengan baterai. Beban yang digunakan yaitu dari 47 Ohm sampai $330 \mathrm{Ohm}$.

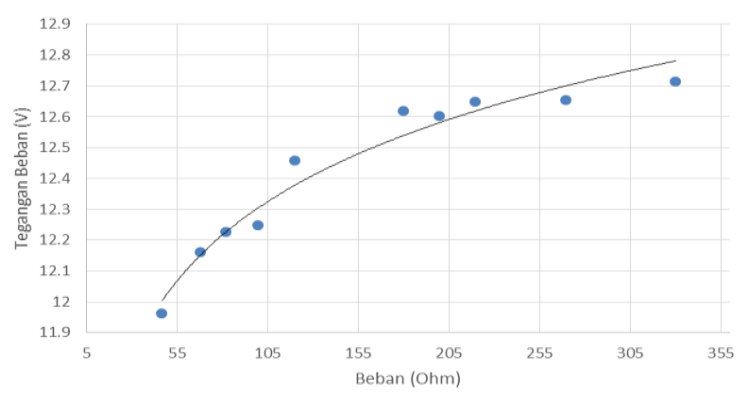

Gambar 6. Hubungan beban dengan tegangan beban rangkaian cut off dengan baterai 1.2 Ah menggunakan beban

Gambar 6 merupakan hubungan antara beban dengan tegangan beban, dapat dilihat bahwa beban dengan tegangan beban berbanding lurus, semakin naik beban maka tegangan beban juga semakin naik. Beban mulai dari 47 Ohm sampai $330 \mathrm{Ohm}$. Pada beban terkecil 47 Ohm tegangannya yaitu $11.960 \mathrm{~V}$ dan pada beban terbesar $330 \mathrm{Ohm}$ tegangannya yaitu $12.714 \mathrm{~V}$.

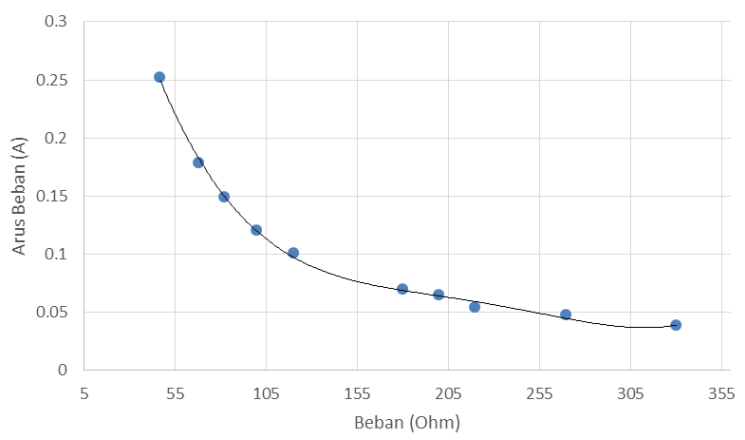

Gambar 7. Hubungan beban dengan arus beban rangkaian cut off dengan baterai 1.2 Ah menggunakan beban

Gambar 7 merupakan hubungan antara beban dengan arus beban, dapat dilihat bahwa beban dengan arus beban berbanding terbalik, semakin naik beban maka arus beban semakin turun. Beban mulai dari 47 Ohm sampai 330 Ohm. Pada beban terkecil $47 \mathrm{Ohm}$ arusnya yaitu 0.2520 A dan pada beban terbesar $330 \mathrm{Ohm}$ arusnya yaitu 0.0383 A.

\subsection{Pengujian Pengisian Baterai}

Pengujian ini merupakan pengujian pengisian baterai dengan baterai 1.2 Ah. Tegangan dan arus diukur menggunakan multimeter SANWA PC5000 dengan probe 
tegangan dihubung paralel dengan probe arus dihubung seri dengan baterai. Berikut merupakan data yang diambil pada pengisian baterai dengan baterai 1.2 Ah

Tabel 3. Data pengujian pengisian baterai 1.2 Ah.

\begin{tabular}{|c|c|c|c|c|}
\hline Menit & $\begin{array}{l}\text { I Pengisian } \\
\text { (A) }\end{array}$ & $\begin{array}{l}\text { V Baterai } \\
\text { (V) }\end{array}$ & $\begin{array}{l}\text { I Baterai } \\
\text { (A) }\end{array}$ & $\begin{array}{l}\text { V Open } \\
\text { Circuit } \\
\text { (V) }\end{array}$ \\
\hline 0 & 0.80 & 13.532 & 0.8286 & 11.146 \\
\hline 5 & 0.87 & 13.591 & 0.8969 & \\
\hline 10 & 0.76 & 13.677 & 0.7808 & \\
\hline 15 & 0.65 & 13.730 & 0.6752 & \\
\hline 20 & 0.54 & 13.774 & 0.5604 & \\
\hline 25 & 0.47 & 13.808 & 0.4880 & \\
\hline 30 & 0.40 & 13.860 & 0.4214 & \\
\hline 35 & 0.33 & 13.890 & 0.3548 & \\
\hline 40 & 0.24 & 13.933 & 0.2752 & \\
\hline 45 & 0.18 & 13.963 & 0.2106 & \\
\hline 50 & 0.16 & 13.981 & 0.1832 & \\
\hline 55 & 0.12 & 13.998 & 0.1439 & \\
\hline 60 & 0.09 & 14.016 & 0.1190 & \\
\hline 65 & 0.08 & 14.014 & 0.1006 & 13.098 \\
\hline 70 & 0.06 & 14.025 & 0.0827 & \\
\hline 75 & 0.05 & 14.028 & 0.0767 & \\
\hline 80 & 0.04 & 14.033 & 0.0689 & \\
\hline 85 & 0.03 & 14.041 & 0.0594 & \\
\hline 90 & 0.03 & 14.040 & 0.0558 & \\
\hline 95 & 0.03 & 14.040 & 0.0523 & \\
\hline 100 & 0.02 & 14.042 & 0.0478 & \\
\hline 105 & 0.02 & 14.043 & 0.0427 & \\
\hline 110 & 0.02 & 14.041 & 0.0422 & \\
\hline 115 & 0.01 & 14.028 & 0.0395 & \\
\hline 120 & 0.01 & 14.023 & 0.0392 & 13.051 \\
\hline
\end{tabular}

Pada tabel 3 dapat dilihat bahwa tegangan pada saat open circuit yaitu pada menit 0 yaitu $11.146 \mathrm{~V}$. Pada menit yaitu $13.098 \mathrm{~V}$, dan pada menit yaitu $13.051 \mathrm{~V}$.

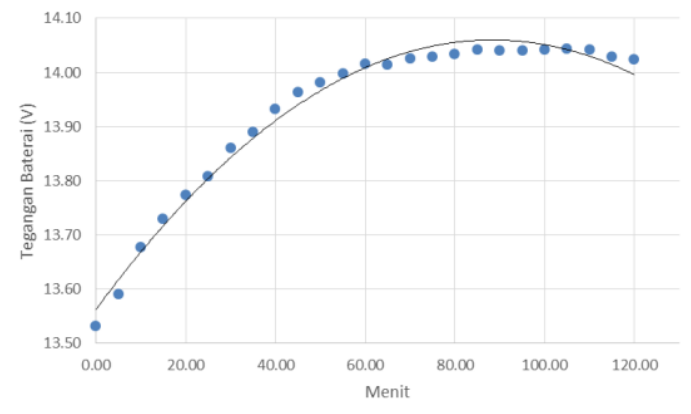

Gambar 8 Hubungan waktu pengisian dengan tegangan baterai pengisian baterai $1.2 \mathrm{Ah}$

Gambar 8 merupakan hubungan antara waktu pengisian dengan tegangan baterai, dapat dilihat bahwa waktu pengisian dengan tegangan baterai berbanding lurus, semakin naik waktu maka tegangan baterai juga semakin naik. Waktu pengisian dimulai pada menit 0 dan selesai menit 120. Pada menit 0 tegangan baterai sebesar 13.532 $\mathrm{V}$ dan pada menit 120 sebesar $14.023 \mathrm{~V}$.



Gambar 9. Hubungan waktu pengisian dengan arus baterai pengisian baterai $1.2 \mathrm{Ah}$

Gambar 9 merupakan hubungan antara waktu pengisian dengan arus baterai, dapat dilihat bahwa waktu pengisian dengan arus baterai berbanding terbalik, semakin naik waktu arus baterai semakin turun. Waktu pengisian dimulai pada menit 0 dan selesai pada menit 120. Pada menit 0 arus baterai sebesar 0.80 A dan pada menit 120 sebesar $0.01 \mathrm{~A}$

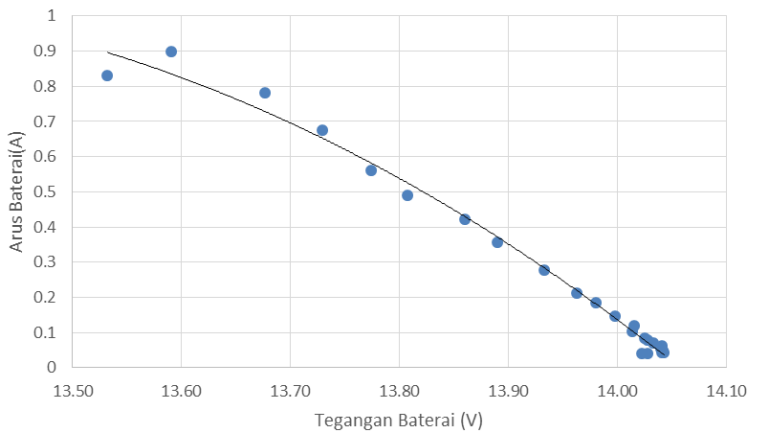

Gambar 10. Hubungan tegangan baterai dengan arus baterai pengisian baterai 1.2 Ah

Gambar 10 merupakan hubungan antara tegangan baterai dengan arus baterai, dapat dilihat bahwa tegangan baterai dengan arus baterai berbanding terbalik, semakin naik tegangan baterai maka arus baterai semakin turun. Pada tegangan baterai terkecil $13.532 \mathrm{~V}$ arusnya yaitu $0.8 \mathrm{~A}$ sedangkan pada tegangan baterai terbesar $14.023 \mathrm{~V}$ arusnya yaitu $0.01 \mathrm{~A}$

\subsection{Pengujian Pengosongan Baterai}

Pengujian ini merupakan pengujian pengosongan baterai dengan baterai 1.2 Ah. Tegangan dan arus diukur menggunakan multimeter SANWA PC5000 dengan probe tegangan dihubung paralel dengan probe arus dihubung seri dengan baterai . Berikut merupakan data yang diambil pada pengosongan baterai dengan baterai 1.2 Ah 
TRANSIENT, VOL. 7, NO. 4, DESEMBER 2018, ISSN: 2302-9927, 916

Tabel 4. Data pengujian pengosongan baterai 1.2 Ah.

\begin{tabular}{llll}
\hline Menit & $\begin{array}{l}\text { V Baterai } \\
\text { (V) }\end{array}$ & $\begin{array}{l}\text { IBaterai } \\
\text { (A) }\end{array}$ & $\begin{array}{l}\text { V } \\
\text { Open Circuit } \\
\text { (V) }\end{array}$ \\
\hline 0 & 12.452 & 0.2376 & 12.750 \\
5 & 12.389 & 0.2173 & \\
10 & 12.352 & 0.2166 & \\
15 & 12.295 & 0.216 & \\
20 & 12.287 & 0.2162 & \\
25 & 12.250 & 0.2151 & \\
30 & 12.221 & 0.2158 & \\
35 & 12.184 & 0.2151 & \\
40 & 12.150 & 0.2150 & \\
45 & 12.113 & 0.2145 & \\
50 & 12.085 & 0.2142 & \\
55 & 12.064 & 0.2139 & \\
60 & 12.002 & 0.2133 & 12.162 \\
65 & 11.965 & 0.2124 & \\
70 & 11.928 & 0.2117 & \\
75 & 11.867 & 0.2114 & \\
80 & 11.838 & 0.2107 & \\
85 & 11.799 & 0.2098 & \\
90 & 11.752 & 0.2090 & \\
95 & 11.713 & 0.2089 & \\
100 & 11.629 & 0.2076 & \\
105 & 11.536 & 0.2072 & \\
110 & 11.455 & 0.2069 & \\
115 & 11.344 & 0.2040 & \\
120 & 11.090 & 0.2008 & 11.438 \\
\hline
\end{tabular}

Pada tabel 4 dapat dilihat bahwa pengosongan baterai 1.2 Ah dimulai pada menit 0 dan berakhir pada menit 120 . Dapat dilihat bahwa tegangan pada saat open circuit yaitu pada menit 0 yaitu $12.750 \mathrm{~V}$. Pada menit 60 yaitu 12.162 $\mathrm{V}$, dan pada menit 120 yaitu $11.438 \mathrm{~V}$.

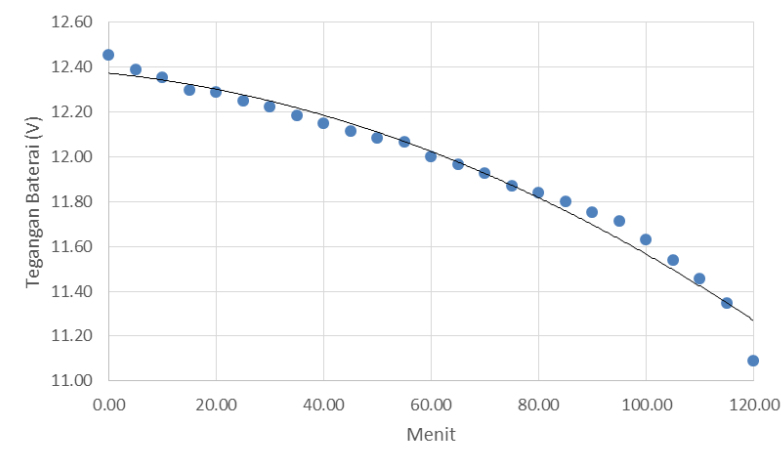

Gambar 11 Hubungan waktu pengosongan dengan tegangan baterai pengosongan baterai $1.2 \mathrm{Ah}$

Gambar 11 merupakan hubungan antara waktu pengosongan dengan tegangan baterai, dapat dilihat bahwa waktu pengosongan dengan tegangan baterai berbanding terbalik, semakin naik waktu pengosongan maka tegangan baterai semakin turun. Waktu pengosongan dimulai pada menit 0 dan selesai pada menit 120. Pada menit 0 tegangan baterai sebesar $12.452 \mathrm{~V}$ dan pada menit 120 sebesar $11.090 \mathrm{~V}$.

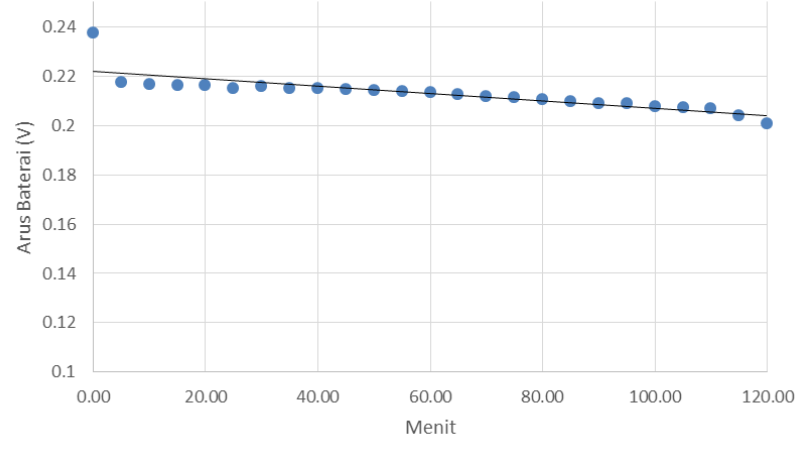

Gambar 12. Hubungan waktu pengosongan dengan arus baterai pengosongan baterai $1.2 \mathrm{Ah}$

Gambar 12 merupakan hubungan antara waktu pengosongan dengan arus baterai, dapat dilihat bahwa arus baterai cenderung stabil dan hanya mengalami sedikit penurunan. Waktu pengosongan dimulai pada menit 0 dan selesai pada menit 120 . Pada menit 0 arus baterai sebesar 0.2376 A dan pada menit 120 sebesar $0.2008 \mathrm{~A}$

\section{Kesimpulan}

Berdasarkan pengukuran dan analisis yang telah dilakukan maka dapat disimpulkan bahwa rangkaian $C u t$ Off telah direalisasikan. Rangkaian Cut Off mampu memutus arus dan tegangan pada kondisi tanpa beban dengan baterai 1.2 Ah yaitu pada tegagan $13.4 \mathrm{~V}$ dan arus 0.012 A. Pada pengujian rangkaian Cut Off menggunakan beban tegangan berbanding lurus dengan beban, yaitu semakin tinggi beban maka tegangan juga akan semakin tinggi.Sedangkan arus berbanding terbalik dengan beban, yaitu semakin tinggi beban maka arus akan semakin turun.Pada pengujian pengisian baterai tegangan berbanding lurus dengan waktu, yaitu semakin naik waktu maka tegangan akan semakin tinggi. Pada pengujian pengosongan baterai tegangan berbanding terbalik dengan waktu, yaitu semakin naik waktu maka tegangan akan semakin rendah. Upaya pengembangan sistem dan hardware lebih lanjut, maka dapat diberikan saran-saran bahwa penelitian ini dapat dikembangkan lagi variasi rangkaian Cut Off lainnya.

\section{Referensi}

[1]. Putra, Hermawan Permana, Studi Karakteristik Pelepasan Muatan Baterai Lead Acid Terhadap Variasi Beban RLC, Skripsi S-1, Universitas Indonesia, Depok, 2010

[2]. A. P. Adityawan, D. C. H, and L. Sulistijono, "SISTEM PENGISIAN BATTERAY LEAD ACID."

[3]. P. Basics and O. Modes, Handbook for Stationary LeadAcid Batteries, no. February, pp. 1-98, 2012.

[4]. Hawker Batteries Handbook, Hawker Group, Chippenham, 1999 
[5]. A. D. N, M. Facta, and A. Nugroho, "Aplikasi konverter jenis push-pull dengan relai pemutus otomatis sebagai pengisi akumulator."

[6]. J. Amateur, "OutBox Project: Membuat Charger Aki Otomatis/ Auto Cut Off Charger Circuit," 2018.Available:https://outboxproject.blogspot.com/2015 /03/charger-aki-otomatis-auto-cutoff.html.
[7]. W. Budiman and N. Hariyanto, "Perancangan dan Realisasi Sistem Pengisian Baterai 12 Volt 45 Ah pada Pembangkit Listrik Tenaga Pikohidro di UPI Bandung," Bandung Inst. Teknol. Nas., vol. 2, no. 1, pp. 1-12, 2014.

[8]. FAIRCHILD SEMICONDUCTOR, "LM78XX Datasheet," vol. 23, no.April 1999,p 18, 1999

[9]. ON-Semiconductor, "Plastic mediumpower,"Semicond.,vol.122,pp 1-7,2014. 